\title{
The impact of asymmetry on equilibrium of logistics systems
}

\author{
Irina Savelieva ${ }^{1, *}$, Serhij Melnikov ${ }^{1}$, and Alexandra Orlovska ${ }^{2}$ \\ ${ }^{1}$ ONMU, Chair of Entrepreneurship \& Tourism, 65029 Odessa, Mechnikov Str., 34, Ukraine \\ ${ }^{2}$ DNURT, Lviv branch, 79052 Lviv, I. Blazhkevich Str., 12a, Ukraine
}

\begin{abstract}
The article examines one of the actual problems of the theory and practice of the logistics systems functioning related to the asymmetry of information in the transport services market. Assessing the level of asymmetry in logistics systems is of fundamental importance to increase the competitiveness of relevant systems. New approach formulated herein estimates the logistics systems asymmetry by taking into account information asymmetry about the quality of transport products, as well as information asymmetry about the quality of products within the boundaries of the corresponding supply chain. This approach allows to take into account its potential capabilities and increase functional stability in the process of logistics systems design.
\end{abstract}

\section{Introduction}

The basis of a classical economic theory is the assumption of a completeness and accuracy of information held by the economic agents. Based on this assumption, a conclusion is made about the principal possibility of rational behavior of economic agents and achieving the Pareto efficiency. However, this assumption does not correspond to economic reality and a lot of research in the twentieth century was devoted to the impact of informational and other types of asymmetry in market processes. The result of this research was the first in this century, the Nobel Prize in economics that was awarded Akerlof, Spence, and Stiglitz for the development of the theory of markets with asymmetric information.

Note that until now there is no clear agreement on the role of asymmetric information in market processes. For Akerlof, the asymmetric information plays a negative role, prevents economic agents from making rational decisions, restricts the effective allocation of resources, and therefore needs state regulation. Another viewpoint on the role of the asymmetric information was expressed by Hayek [1] - the Nobel Prize winner of 1974. They believe that it is the asymmetric information that is the prerequisite for the existence of markets and profit for entrepreneurs.

Asymmetry is one of the problems that hinders the sustainable development of logistics systems. An important step in solving this problem is to develop a theoretical basis for determining the extent to which the asymmetry is assessed.

The functionality of logistics systems is affected by the following types of information asymmetry related to quality:
1) information asymmetry of the quality of goods between producers and consumers within the relevant supply chains;

2) information asymmetry regarding the quality of transport products between the participants of the market of transport services: state authorities, cargo owners, carriers, logistics centers, intermediaries;

3 ) both types of asymmetry combined.

Indicators of information asymmetry in the market of logistics services should include:

- regularity and timeliness of transportation;

- delivery time;

- quality and conditions of cargo storage;

- vehicles traffic safety;

- schedule reliability and speed of passenger transportation;

- passengers comfort and service level throughout the route;

- guarantees of carrying out of the reloading process in the specified time in the logistic centers;

- possibility to receive in the real time information about cargo operations,

- presence of specialized equipment with the required technical characteristics in the logistics centers,

- availability and quality of additional operations and services.

All these indicators have a direct impact on the financial performance of economic agents of the logistics system.

In this paper, we consider a duopoly model of supply chains, which compete under conditions of the impact of real and information asymmetries. The equilibrium states of Cournot and Stackelberg are determined and the influence of all asymmetries is explicitly shown.

Akerlof was the first one to describe the impact of asymmetric information on market equilibrium. In his seminal work [2], Akerlof formalized the adverse

* Corresponding author: savirina@gmail.com 
selection that occurs in the used car market with the asymmetry of information about car quality between supply chain and buyer.

Vives [3] considers the impact of private information about an uncertain linear demand on Cournot and Bertrand equilibria in the duopoly model. It is shown that if the goods are substitutes (not) to share information is a dominant strategy for each firm in Bertrand (Cournot) competition. In her work, Gal-or [4] examines the impact of cost information asymmetry on Cournot and Bertrand equilibria in the duopoly model. The author investigates how incentives for two duopolists to honestly share information change depending upon the type of equilibrium. Roller and Sinclair-Desgagne [5] have analyzed the sources of persistent asymmetry between firms and between markets in a Cournot's duopoly model.

Zanchettin [6] analyzed the impact of cost asymmetry and demand asymmetry on Bertrand and Cournot equilibria in a differentiated duopoly. The paper has shown that both the efficient firm's and industry profits are higher under Bertrand competition when asymmetry is strong and/or products are weakly differentiated. Wang at el. [7] has proposed an agentbased model to study the impact of asymmetric information on market evolution. The model proposed is able to demonstrate how the asymmetry of information leads to the adverse selection effect. The model also explains the coexistence of low- and high-quality goods in a market with asymmetric information. Ledvina and Sircar [8] have investigated how costs asymmetry impact on entry/exit decisions of firms at Cournot and Bertrand equilibria. The paper shows that due of cost asymmetry the differentiated goods result in more active firms in equilibrium than homogeneous goods.

Nagurney at el. [9] have developed a spatial price equilibrium model with information asymmetry in quality in that the producers at the supply markets are aware of their product quality whereas consumers at the demand markets are only aware of the average quality of the products. In the paper provided qualitative analysis of conditions for existence and uniqueness of equilibria as well as stability analysis for the solutions. Wang [10] has examined a supply chain model consisting of a dominant supplier and a buyer, in which the latter possesses superior knowledge of his private cost information. The supplier's imperfect knowledge about the buyer's cost is described by a uniform distribution. In the paper derived the explicit expressions of the optimal equilibrium outcomes of two contract formats offered by the supplier, the simple price-only contract and sophisticated menu of contracts, respectively.

Brangewitz and Manegold [11] have analyzed the impact of quality asymmetry on Cournot and Bertrand equilibria in an intermediate goods market. Melnikov [12] has investigated Cournot and Stackelberg equilibria in the duopoly model under conditions of asymmetric information of quality. It has found that optimal for both duopolists is a Stackelberg equilibrium when the leader is a manufacturer of high-quality good. It is received that adverse selection effects all equilibrium states.
Based on the analysis of the literature, the following types of the asymmetries impact on market equilibrium can be distinguished.

The first type is the impact of real asymmetries. This is the asymmetry of the values of market indicators. This asymmetry type is natural and always present in the economy. The examples of indicators at the micro level: costs, quality level, prices, activity strategy, production capacities, volumes of activity, location, etc., at the macro level: gross national income, gross regional product, equilibrium state (stability), a degree of monopolization, etc.

The second type is the impact of information asymmetries. This is the asymmetry of completeness, reliability and an availability of information between economic agents about market indicators. For example, asymmetry of Akerlof (asymmetry of information about a quality of goods between a seller and a buyer) and Stackelberg (asymmetry of information about a competitor's strategy between sellers).

The third type is the simultaneous impact of real and information asymmetries. An example of this is, the classical model from [2], where there is a real asymmetry of quality and asymmetry of information about quality.

In [12], the authors found that the Stackelberg asymmetry does not help the high-quality seller overcome the Akerlof asymmetry and earn more than a competitor. The leadership of a high-quality seller paradoxically increases a profit of the low-quality seller under conditions of the Akerlof asymmetry.

It is of interest to develop the results obtained by Melnikov [12] to the case of a location asymmetry between supply chains. The aim of this paper is the analysis of the asymmetry impact on equilibrium states in the duopoly model of supply chains.

\section{The model}

Two supply chains sell similar goods in the same markets, $m=2 \cdot n+1, \quad n \in N, N$ - set of natural numbers. Markets are located along a line, the distance between any neighboring markets is $l$.

One of the supply chains sells low-quality goods (index 0 ), the other - high-quality goods (index 1). The relationship between goods quality levels is described by the quality asymmetry coefficient, $k>1$. Assume that all unit costs of high-quality goods are higher in $k$ times comparison with low-quality goods.

Transportation delivery costs per unit of the lowquality product per unit distance are equal $t$. Deliveries are made on a DDP agreement, goods stocks of supply chains are unlimited.

Preferences of consumers in each market are described by the Cobb-Douglas utility function. In these conditions, the demand for goods is expressed by isoelastic functions. Consumers have full information about quality and form a separate demand for lowquality goods: $p_{0}=1 / q_{0}$, and high-quality goods: $p_{1}=k / q_{1}$, where $p_{0}, p_{1}-$ market prices, $q_{0}, q_{1}-$ 
quantity supplied. Consumers are willing to pay for the same volume of high-quality goods $k$ times greater. In each market, prices and sales volumes are the same.

We introduce into the model the location asymmetry. Location asymmetry arises when one of the supply chains has a competitive advantage because of their location. In this model, location asymmetry is measured by the ratio of the total distance of supply chains' transportations and depends on their location and the number of markets.

Assume that the low-quality supply chain is located on the 1st market, and the high-quality supply chain is located at the center, of the market with index $(m+1) / 2$ (Fig.1).

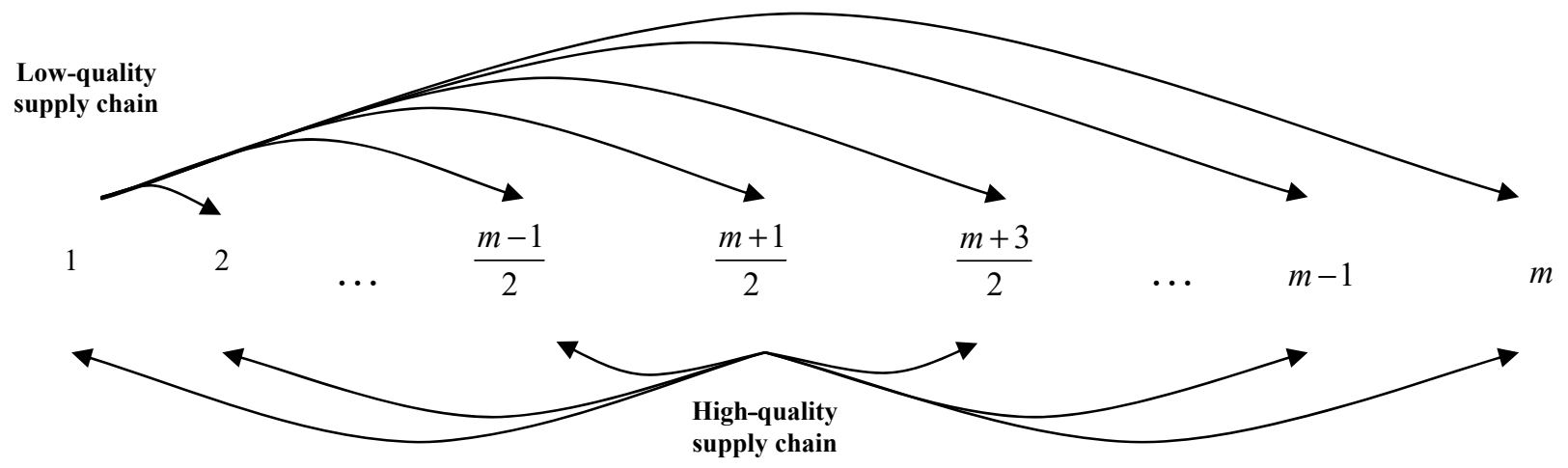

Fig. 1. Location of supply chains

Obviously, the low-quality supply chain has a maximum and the high-quality supply chain has a minimum delivery distance of goods. The total transportation distance of the high-quality supply chain is: $L=l \cdot\left(m^{2}-1\right) / 4$, low-quality supply chain: $d \cdot L$, where $\quad d=2 \cdot m /(m+1) \quad-\quad$ location asymmetry coefficient, $d \in[1,5 ; 2)$.

In conditions of complete information about goods quality the supply chains are monopolists. The profit functions that need maximizing over the quantities supplied for each supply chain are given by:

$$
\begin{gathered}
F_{0}^{\text {mono }}=q_{0} \cdot\left(m \cdot \frac{1}{\mathrm{q}_{0}}-t \cdot d \cdot L\right) \rightarrow \max _{q_{0}}, \\
F_{1}^{\text {mono }}=q_{1} \cdot\left(m \cdot \frac{k}{q_{1}}-t \cdot k \cdot L\right) \rightarrow \max _{q_{1}}
\end{gathered}
$$

From (1) we see that for identical volumes of sales, $\mathrm{q}_{0}=q_{1}$, a profit of the high-quality supply chain is always higher than the low-quality supply chain. The real asymmetries of quality and location "work" in favor of the high-quality supply chain: $\partial F_{0} / \partial d<0$, $\partial F_{1} / \partial \mathrm{k}>0$.

\section{The impact of Akerlof information asymmetry}

Suppose that the low-quality supply chain began to advertise its product as a quality one. If consumers cannot distinguish a quality of goods, then the Akerlof information asymmetry of arises. In conditions of the Akerlof asymmetry, consumers form the demand for both goods already in the form of a single function: $p=(1-\alpha) \cdot p_{0}+\alpha \cdot p_{1}=(k+1) /\left(q_{0}+q_{1}\right), \quad$ where $\alpha=q_{1} /\left(q_{0}+q_{1}\right)-$ market share of the high-quality goods, $(1-\alpha)-$ market share of the low-quality goods.

In conditions of incomplete information about goods quality the supply chains are duopolists. The profit functions:

$$
\begin{aligned}
& F_{0}^{\text {duo }}=q_{0} \cdot\left(\mathrm{m} \cdot \frac{k+1}{q_{0}+q_{1}}-t \cdot d \cdot L\right) \rightarrow \max _{q_{0}}, \\
& F_{1}^{d u o}=q_{1} \cdot\left(m \cdot \frac{k+1}{q_{0}+q_{1}}-t \cdot k \cdot L\right) \rightarrow \max _{q_{1}} .
\end{aligned}
$$

Let us find the Cournot equilibrium and analyze how the Akerlof asymmetry affects the profits of supply chains and impact of real asymmetries. Putting the first derivatives, $\partial F_{0}^{\text {duo }} / \partial q_{0}=0$ and $\partial F_{1}^{d u o} / \partial q_{1}=0$, and solving for $q_{0}, q_{1}$ one obtains:

$$
q_{0}^{*}=\sqrt{\frac{m \cdot(k+1) \cdot q_{1}}{t \cdot d \cdot L}}-q_{1}, q_{1}^{*}=\sqrt{\frac{m \cdot(k+1) \cdot q_{0}}{t \cdot k \cdot L}}-q_{0},
$$

which are the reaction functions.

The second derivatives are negative, $d^{2} F_{0} / d q_{0}^{2}<0$, $d^{2} F_{1} / d q_{1}^{2}<0$, what means the profit functions of reach a maximum.

Let us find the following indicators (Table 1):

- the range of permissible values of the quality asymmetry coefficient $k$;

- the sales volumes: $q_{0}^{e}, q_{1}^{e}, Q^{e}=q_{0}^{e}+q_{1}^{e}$;

- the profits: $F_{0}^{e}, F_{1}^{e}$;

- the prices under conditions of effect of the Akerlof asymmetry $p^{e}$ and in its absence $p_{0}^{e}, p_{1}^{e}$;

- the market share of high-quality goods $\alpha^{e}$; 
- the Akerlof point $k^{e}$. The Akerlof point corresponds to the value of the quality asymmetry coefficient, in which the duopoly disappears ("market failure"). A sign of the Akerlof point will be considered the absence of sales or profit or loss of equilibrium stability;

- the market share of high-quality goods in the Akerlof point $\alpha^{e}\left(k^{e}\right)$.

Table 1. The Cournot equilibrium

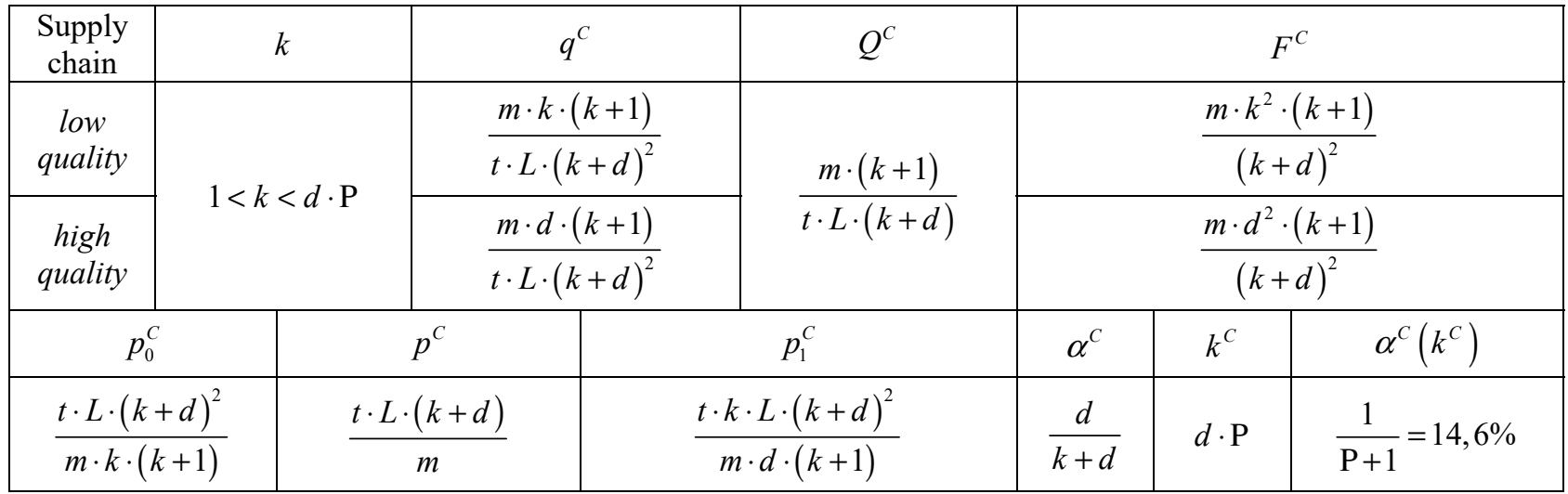

Let us analyze the results obtained. To analyze the impact of the Akerlof asymmetry on the profit of the low-quality supply chain, we calculate the coefficient: $A_{0}=\mathrm{p}^{C} / p_{0}^{C}=k \cdot(k+1) /(k+d)$, where $p_{0}^{C} \quad$ - the selling price of the low-quality good in volume $q_{0}^{C}$ in the absence of the Akerlof asymmetry. Then the profit of the low-quality supply chain can be represented in the form:

$$
F_{0}^{C}=q_{0}^{C} \cdot\left(m \cdot A_{0} \cdot p_{0}^{C}-t \cdot d \cdot L\right)
$$

The impact of the coefficient $A_{0}$ on profit (3) is determined by conditions: $\partial A_{0} / \partial k>0, \partial A_{0} / \partial d<0$, $\operatorname{sign}\left(A_{0}-1\right)=\operatorname{sign}(k-\sqrt{d})$. Because of location asymmetry, the low-quality supply chain benefits from the Akerlof asymmetry only when $k>\sqrt{d}$. At $k=\sqrt{d}$, the Akerlof asymmetry does not affect profit: $F_{0}^{\text {mono }}\left(q_{0}^{C}\right)=F_{0}^{C}\left(q_{0}^{C}\right)$.

To analyze the impact of the Akerlof asymmetry on profit of the high-quality supply chain, we calculate the coefficient: $A_{1}=p^{C} / p_{1}^{C}=d \cdot(k+1) /(k \cdot(k+d))$, where $p_{1}^{C}$ - the selling price of the high-quality good in volume $q_{1}^{C}$ in the absence of the Akerlof asymmetry. Then the profit of the high-quality supply chain can be represented in the form:

$$
F_{1}^{C}=q_{1}^{C} \cdot\left(m \cdot A_{1} \cdot \mathrm{p}_{1}^{C}-t \cdot k \cdot L\right)
$$

The impact of the coefficient $A_{1}$ on profit (4) is determined by conditions: $\partial A_{1} / \partial k<0, \partial A_{1} / \partial d>0$, $\operatorname{sign}\left(1-A_{1}\right)=\operatorname{sign}(k-\sqrt{d})$. With the Akerlof asymmetry, the high-quality supply chain benefits from location asymmetry only up to $k<\sqrt{d}$. At $k=\sqrt{d}$, the
Akerlof asymmetry does not affect profit: $F_{1}^{\text {mono }}\left(q_{1}^{C}\right)=F_{1}^{C}\left(q_{1}^{C}\right)$.

From Table 1 it follows that sale volumes and profits at the Cournot equilibrium are always positive. To find the Akerlof point, we will analyze the equilibrium stability. Let us consider the two-dimensional map:

$$
\begin{gathered}
q_{0}^{*}(t+1)=\sqrt{\frac{m \cdot(k+1) \cdot q_{1}(t)}{t \cdot d \cdot L}}-q_{1}(t), \\
q_{1}^{*}(t+1)=\sqrt{\frac{m \cdot(k+1) \cdot q_{0}(t)}{t \cdot k \cdot L}}-q_{0}(t) .
\end{gathered}
$$

The stability of the map fixed point (5), $\left(q_{0}^{C}, q_{1}^{C}\right)$, is defined by multiplicators $\mu_{1}, \mu_{2}$, which are eigenvalues of Jacobian matrix at the fixed point: $J=\left(\begin{array}{cc}0 & \frac{k-d}{2 \cdot d} \\ -\frac{k-d}{2 \cdot k} & 0\end{array}\right)$. The multiplicators are roots $\mu_{1}, \mu_{2}$ of the characteristic equation

$$
\mu^{2}+|J|=\mu^{2}+\frac{(k-d)^{2}}{4 \cdot k \cdot d}=0 .
$$

From (6) it follows that the eigenvalues are pure imaginary, since both $k$ and $d$ are positive. As is known, the boundary of the stability region of a twodimensional map for pure imaginary multiplicators is found from condition $|J|=1$. Equating $|J|=1$, we find the value of the quality asymmetry coefficient at which the Cournot equilibrium loses stability: $k^{C}=d \cdot \mathrm{P}$, where $\mathrm{P}=3+2 \cdot \sqrt{2}$ - the Puu point (bifurcation point in a duopoly model with one market [13]. 
Equating $\mu_{1}=\mu_{2}=0$, we find the value of the quality asymmetry coefficient at which the Cournot equilibrium is a superstable: $k=d$.

The relationship between equilibrium sales volumes depends on the superstable point: $\operatorname{sign}\left(q_{0}^{C}-q_{1}^{C}\right)=\operatorname{sign}(k-\mathrm{d})$. Dynamics of equilibrium sales volumes, depending on the quality asymmetry coefficient, is shown in Fig.2(a). Data: $t=1, l=0,1$, $m=3, k \in(1 ; 9,375]$. The Akerlof point: $k^{C}=8,74$, the superstable point: $k=d=1,5$. An increase in the number of markets leads to a decrease in equilibrium sales volumes and an increase in the level of the Akerlof point. This is clearly seen in the bifurcation diagrams of the high-quality supply chain (Fig.2(b)). Data: $t=1$, $l=0,1, m=3, m=5, k \in[8 ; 10,415]$. The points of Akerlof: $k^{C}(m=3)=8,74, k^{C}(m=5)=9,71$.

From Fig. 2 we see that an increase of investment in quality paradoxically leads to the ousting of high-quality goods from the market. If consumers cannot distinguish the quality of goods, then the high-quality

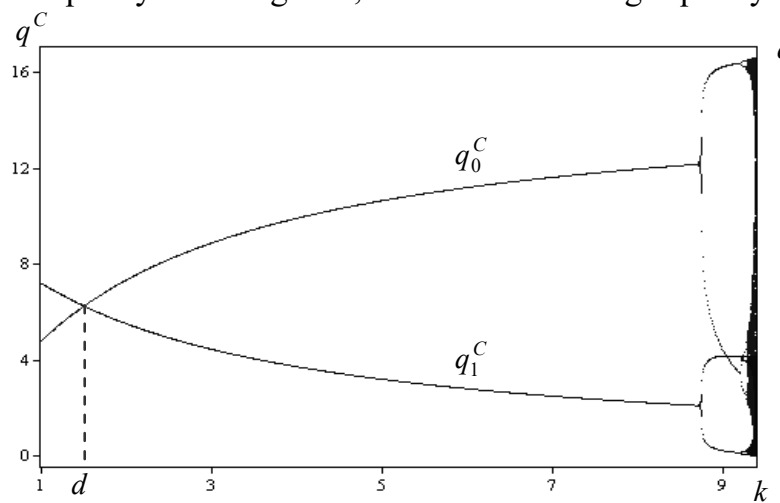

(a) supply chain will either have to leave the market or switch to sale of the low-quality good. As a result, the duopoly is reduced to the market of low-quality goods. Thus, given model illustrates the adverse selection that results from the information asymmetry about quality [2].

\section{The impact of Stackelberg information asymmetry}

Now we introduce into the model the Stackelberg information asymmetry. Stackelberg information asymmetry arises when one of the supply chains (leader) knows the competitor's reaction curve, and competitor (follower) does not own such information. Assume that the low-quality supply chain is a leader, and the highquality supply chain is a follower. The new profit function of the low-quality supply chain is: $F_{0}=\sqrt{t \cdot k \cdot L \cdot m \cdot(k+1) \cdot q_{0}}-t \cdot d \cdot L \cdot q_{0} \rightarrow \max _{q_{0}}$.

Using the standard procedure, we find the equilibrium indicators (Table 2 ).

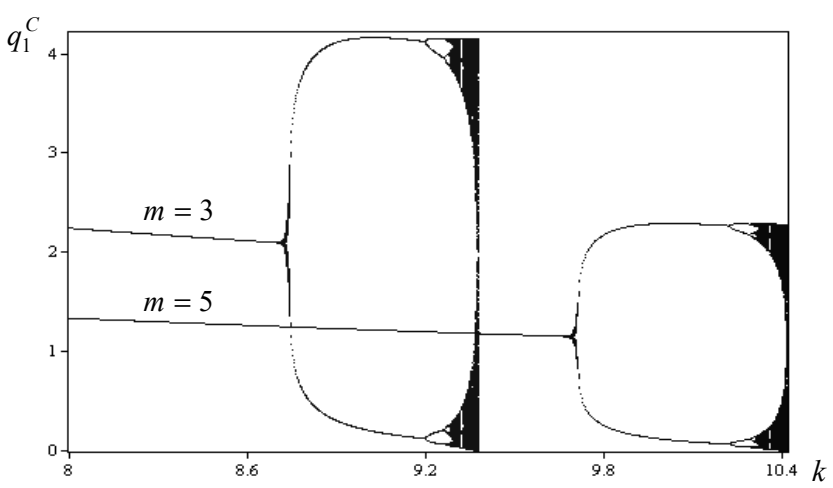

(b)

Fig.2. Bifurcation diagrams of supply chains

Table 2. The Stackelberg equilibrium, leader is the low-quality supply chain

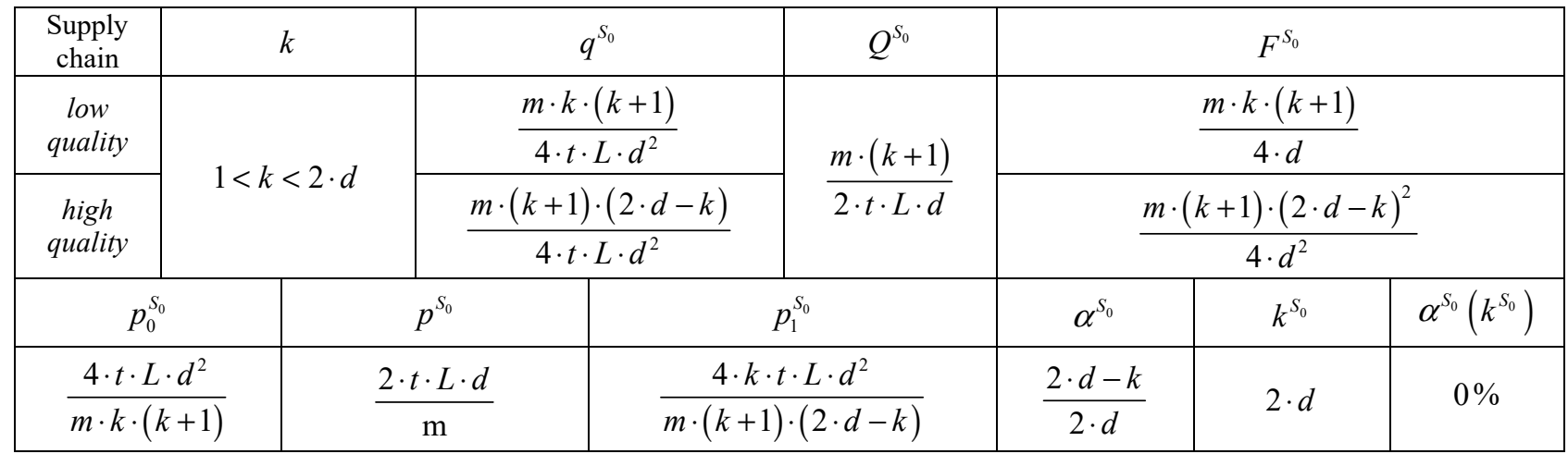

Let us analyze how a leadership of the low-quality supply chain affects the Cournot equilibrium. The impact on the equilibrium price we express in the form of a coefficient, which is defined as: $S_{p}^{0}=\mathrm{p}^{S_{0}} / p^{C}=2 \cdot d /(k+d)$, where the superscript indicates the leader, and the lower index indicates the influence indicator. The impact of real asymmetries on the equilibrium price is determined by conditions: $\partial S_{p}^{0} / \partial k<0, \partial S_{p}^{0} / \partial d>0, \operatorname{sign}\left(1-S_{p}^{0}\right)=\operatorname{sign}(k-d)$.

The impact on the sales volume of the low-quality supply chain we express in the form of a coefficient, 
which is defined as: $S_{q_{0}}^{0}=q_{0}^{S_{0}} / q_{0}^{C}=(k+d)^{2} /\left(4 \cdot d^{2}\right)$. Then the profit of the low-quality supply chain can be represented in the form:

$$
F_{0}^{S_{0}}=S_{q_{0}}^{0} \cdot q_{0}^{C} \cdot\left(m \cdot S_{p}^{0} \cdot p^{C}-t \cdot d \cdot L\right)
$$

The impact of the coefficient $S_{q_{0}}^{0}$ on profit (7) is determined by conditions: $\partial S_{q_{0}}^{0} / \partial k>0, \partial S_{q_{0}}^{0} / \partial d<0$, $\operatorname{sign}\left(S_{q_{0}}^{0}-1\right)=\operatorname{sign}(k-d)$. At $k=d$, the Stackelberg asymmetry does not affect profit: $F_{0}^{S_{0}}\left(q_{0}^{S_{0}}\right)=F_{0}^{C}\left(q_{0}^{C}\right)$.

The impact on the sales volume of the high-quality supply chain we express in the form of a coefficient, which is defined as: $S_{q_{1}}^{0}=q_{1}^{S_{0}} / q_{1}^{C}=(2 \cdot d-k) \cdot(k+d)^{2} /\left(4 \cdot d^{3}\right)$. Then the profit of the high-quality supply chain can be represented in the form:

$$
F_{1}^{S_{0}}=S_{q_{1}}^{0} \cdot q_{1}^{C} \cdot\left(m \cdot S_{p}^{0} \cdot p^{C}-t \cdot k \cdot L\right) .
$$

The impact of the coefficient $S_{q_{1}}^{0}$ on profit (8) is determined by conditions: $\operatorname{sign}\left(\partial S_{q_{1}}^{0} / \partial \mathrm{d}\right)=\operatorname{sign}(k-d)$, $\operatorname{sign}\left(\partial S_{q_{1}}^{0} / \partial k\right)=\operatorname{sign}(d-k), \quad S_{q_{1}}^{0} \leq 1$. At $k=d$, the Stackelberg asymmetry does not affect profit: $F_{1}^{S_{0}}\left(q_{1}^{S_{0}}\right)=F_{1}^{C}\left(q_{1}^{C}\right)$.

Assume that the high-quality supply chain is a leader, and the low-quality supply chain is a follower. The new profit function of the high-quality supply chain is: $F_{1}=\sqrt{t \cdot d \cdot L \cdot m \cdot(k+1) \cdot q_{1}}-t \cdot k \cdot L \cdot q_{1} \rightarrow \max _{q_{1}}$.

Using the standard procedure, we find the equilibrium indicators (Table 3 ).

\begin{tabular}{|c|c|c|c|c|c|}
\hline Supply chain & $k$ & $q^{S_{1}}$ & $Q^{S_{1}}$ & \multicolumn{2}{|c|}{$F^{S_{1}}$} \\
\hline low auality & \multirow{4}{*}{$k>1$} & $m \cdot(k+1) \cdot(2 \cdot k-d)$ & \multirow{4}{*}{$\frac{m \cdot(k+1)}{2 \cdot t \cdot L \cdot k}$} & \multirow{2}{*}{\multicolumn{2}{|c|}{$\frac{m \cdot(k+1) \cdot(2 \cdot k-d)^{2}}{4 \cdot k^{2}}$}} \\
\hline tow qualuy & & $4 \cdot t \cdot L \cdot k^{2}$ & & & \\
\hline hioh auality & & $m \cdot d \cdot(k+1)$ & & \multicolumn{2}{|c|}{$m \cdot d \cdot(k+1)$} \\
\hline & & $4 \cdot t \cdot L \cdot k^{2}$ & & \multicolumn{2}{|c|}{$4 \cdot k$} \\
\hline \multicolumn{2}{|c|}{$p_{0}^{S_{1}}$} & \multicolumn{2}{|c|}{$p^{S_{1}}$} & $p_{1}^{S_{1}}$ & $\alpha^{S_{1}}$ \\
\hline \multicolumn{2}{|c|}{$\frac{4 \cdot t \cdot L \cdot k^{2}}{m \cdot(k+1) \cdot(2 \cdot k-d)}$} & \multicolumn{2}{|c|}{$2 \cdot t \cdot L \cdot k$} & $4 \cdot t \cdot L \cdot k^{3}$ & $d$ \\
\hline \multicolumn{2}{|c|}{$m \cdot(k+1) \cdot(2 \cdot k-d)$} & \multicolumn{2}{|c|}{$\mathrm{m}$} & $\overline{m \cdot d \cdot(k+1)}$ & $\overline{2 \cdot k}$ \\
\hline
\end{tabular}

Table 3. The Stackelberg equilibrium, leader is the high-quality supply chain

To determine the Akerlof point in the Stackelberg equilibrium $\left(q_{0}^{S_{1}}, q_{1}^{S_{1}}\right)$, it is necessary to specify the lower boundary of a market share of the high-quality good, at which the supply chain will leave the market.

Let us analyze how the leadership of the high-quality supply chain impacted the Cournot equilibrium. The impact on the equilibrium price we express in the form of a coefficient, which is defined as: $S_{p}^{1}=p^{S_{1}} / p^{C}=2 \cdot k /(k+d)$. The impact of the real asymmetries on the equilibrium price is determined by conditions: $\quad \partial S_{p}^{1} / \partial k>0, \quad \partial S_{p}^{1} / \partial d<0$, $\operatorname{sign}\left(S_{p}^{1}-1\right)=\operatorname{sign}(k-d)$.

The impact on the sales volume of the low-quality supply chain we express in the form of a coefficient, which is defined as: $S_{q_{0}}^{1}=q_{0}^{S_{1}} / q_{0}^{C}=(2 \cdot k-d) \cdot(k+d)^{2} /\left(4 \cdot k^{3}\right)$. Then the profit of the low-quality supply chain can be represented in the form:

$$
F_{0}^{S_{1}}=S_{q_{0}}^{1} \cdot q_{0}^{C} \cdot\left(m \cdot S_{p}^{1} \cdot p^{C}-t \cdot d \cdot L\right)
$$

The impact of the coefficient $S_{\mathrm{q}_{0}}^{1}$ on profit (9) is determined by conditions: $\operatorname{sign}\left(\partial S_{q_{0}}^{1} / \partial k\right)=\operatorname{sign}(d-k)$, $\operatorname{sign}\left(\partial S_{q_{0}}^{1} / \partial d\right)=\operatorname{sign}(k-d), \quad S_{q_{0}}^{1} \leq 1$. At $k=d$, the Stackelberg asymmetry does not affect profit: $F_{0}^{S_{1}}\left(q_{0}^{S_{1}}\right)=F_{0}^{C}\left(q_{0}^{C}\right)$.

The impact on the sales volume of the high-quality supply chain we express in the form of a coefficient, which is defined as: $S_{q_{1}}^{1}=q_{1}^{S_{1}} / q_{1}^{C}=(k+d)^{2} /\left(4 \cdot k^{2}\right)$. Then the profit of the high-quality supply chain can be represented in the form:

$$
F_{1}^{S_{1}}=S_{q_{1}}^{1} \cdot q_{1}^{C} \cdot\left(m \cdot S_{p}^{1} \cdot \mathrm{p}^{C}-t \cdot k \cdot L\right)
$$

The impact of the coefficient $S_{q_{1}}^{1}$ on profit (10) is determined by conditions: $\partial S_{q_{1}}^{1} / \partial k<0, \partial S_{q_{1}}^{1} / \partial d>0$, $\operatorname{sign}\left(1-S_{q_{1}}^{1}\right)=\operatorname{sign}(k-d)$. At $k=d$, the Stackelberg asymmetry does not affect profit: $F_{1}^{S_{1}}\left(q_{1}^{S_{1}}\right)=F_{1}^{C}\left(q_{1}^{C}\right)$.

Thus, information asymmetries can change an action direction of real asymmetries, and real asymmetries can dwindle ("turn off") an action of information asymmetries. 


\section{The comparative analysis of equilibria}

The relationship between sales volumes and profits in different equilibrium states depends significantly on the superstable point. Let us consider all cases.

1) $1<k<\mathrm{d}$. The supply chains' volumes sales: $q_{1}^{S_{1}}>q_{1}^{C}>q_{1}^{S_{0}}>q_{0}^{C}>\left\{q_{0}^{S_{0}} ; q_{0}^{S_{1}}\right\}$,

$\operatorname{sign}\left(q_{0}^{S_{0}}-q_{0}^{S_{1}}\right)=\operatorname{sign}(d \cdot(\Phi-1)-\mathrm{k})$,

where

$\Phi=(1+\sqrt{5}) / 2-$ the golden ratio.

The profits: $\mathrm{F}_{1}^{S_{0}}>\mathrm{F}_{1}^{S_{1}}>\mathrm{F}_{1}^{C}>\mathrm{F}_{0}^{S_{0}}>\mathrm{F}_{0}^{C}>\mathrm{F}_{0}^{S_{1}}$. The prices and total sales: $p^{S_{0}}>p^{C}>p^{S_{1}}, Q^{S_{0}}<\mathrm{Q}^{C}<Q^{S_{1}}$.

Thanks to the location asymmetry, the high-quality supply chain sells more and receives more profit. Note that the optimal for both supply chains is the equilibrium $\left(F_{0}^{S_{0}}, F_{1}^{S_{0}}\right)$. Thus, the profit of the high-quality supply chain on the follower position turned out to be greater than on the leader position.

2) $k=d$. The supply chains' volumes sales: $q_{0}^{C}=q_{0}^{S_{0}}=q_{0}^{S_{1}}=q_{1}^{\mathrm{C}}=q_{1}^{S_{0}}=q_{1}^{S_{1}}=m \cdot(k+1) /(4 \cdot t \cdot L \cdot k)$.

The profits: $F_{0}^{C}=F_{0}^{S_{0}}=F_{0}^{S_{1}}=F_{1}^{C}=F_{1}^{S_{0}}=F_{1}^{S_{1}}=m \cdot(k+1) / 4$. The prices and total sales: $p^{C}=p^{S_{0}}=p^{S_{1}}, \mathrm{Q}^{C}=Q^{S_{0}}=Q^{S_{1}}$.

It is obtained that in a state of the superstable Cournot equilibrium supply chains cannot increase their profits with the help of the Stackelberg asymmetry. In this equilibrium state, a transport costs of the supply chains are equalized, and the real asymmetries compensate each other.

3) $k>d$. The volumes sales: $q_{0}^{S_{0}}>q_{0}^{C}>q_{0}^{S_{1}}>q_{1}^{C}>\left\{q_{1}^{S_{0}}, q_{1}^{S_{1}}\right\}$,

$\operatorname{sign}\left(q_{1}^{S_{1}}-q_{1}^{S_{0}}\right)=\operatorname{sign}(k-d \cdot \Phi)$. The profits: $F_{0}^{S_{1}}>F_{0}^{S_{0}}>F_{0}^{C}>F_{1}^{S_{1}}>F_{1}^{C}>F_{1}^{S_{0}}$. The prices and total sales: $p^{S_{0}}<p^{C}<p^{S_{1}}, Q^{S_{0}}>\mathrm{Q}^{C}>Q^{S_{1}}$.

It is obtained that the high-quality supply chain cannot overcome the Akerlof information asymmetry with the help of the Stackelberg asymmetry. Note that the optimal for both supply chains is the equilibrium $\left(F_{0}^{S_{1}}, F_{1}^{S_{1}}\right)$. Thus, the profit of the low-quality supply chain on the follower position turned out to be greater than on the leader position.

Let us illustrate the comparative analysis of the equilibria on a numerical example (Table 4). Data: $\mathrm{m}=9, t=1,1=0,1, d=1,8$.

Table 4. Numerical example

\begin{tabular}{|c|c|c|c|c|c|c|c|c|c|}
\hline \multirow{3}{*}{ Indicators } & \multicolumn{9}{|c|}{ States of equilibrium } \\
\hline & \multicolumn{3}{|c|}{$1<\mathrm{k}<\mathrm{d}, \mathrm{k}=\mathrm{d} \cdot(\Phi-1)$} & \multicolumn{3}{|c|}{$k=d=1,8$} & \multicolumn{3}{|c|}{$\mathrm{k}>\mathrm{d}, \mathrm{k}=2,2$} \\
\hline & $C$ & $S_{0}$ & $S_{1}$ & $C$ & $S_{0}$ & $S_{1}$ & $C$ & $S_{0}$ & $S_{1}$ \\
\hline$q_{0}^{e}$ & 1,247 & 0,816 & 0,816 & 1,750 & 1,750 & 1,750 & 1,980 & 2,444 & 1,934 \\
\hline$q_{1}^{e}$ & 2,017 & 1,825 & 3,457 & 1,750 & 1,750 & 1,750 & 1,620 & 1,556 & 1,339 \\
\hline$Q^{e}$ & 3,264 & 2,641 & 4,273 & 3,500 & 3,500 & 3,500 & 3,600 & 4,000 & 3,273 \\
\hline$F_{0}^{e}$ & 2,774 & 2,938 & 0,693 & 6,300 & 6,300 & 6,300 & 8,712 & 8,800 & 10,056 \\
\hline$F_{1}^{e}$ & 7,262 & 9,077 & 7,691 & 6,300 & 6,300 & 6,300 & 5,832 & 4,356 & 5,891 \\
\hline$p_{0}\left(q_{0}^{e}\right)$ & 0,802 & 1,226 & 1,226 & 0,571 & 0,571 & 0,571 & 0,505 & 0,409 & 0,517 \\
\hline$p^{e}$ & 0,647 & 0,800 & 0,494 & 0,800 & 0,800 & 0,800 & 0,889 & 0,800 & 0,978 \\
\hline$p_{1}\left(q_{1}^{e}\right)$ & 0,551 & 0,610 & 0,322 & 1,029 & 1,029 & 1,029 & 1,358 & 1,414 & 1,643 \\
\hline$\alpha$ & 0,618 & 0,691 & 0,809 & 0,500 & 0,500 & 0,500 & 0,450 & 0,389 & 0,409 \\
\hline$A_{0}\left(A_{1}\right)$ & \multicolumn{3}{|c|}{$0,807(1,174)$} & \multicolumn{3}{|c|}{$1,400(0,778)$} & \multicolumn{3}{|c|}{$1,760(0,655)$} \\
\hline$S_{p}^{0}\left(S_{p}^{1}\right)$ & \multicolumn{3}{|c|}{$1,236(0,764)$} & \multicolumn{3}{|c|}{$1,000(1,000)$} & \multicolumn{3}{|c|}{$0,900(1,100)$} \\
\hline$S_{q_{0}}^{0}\left(S_{q_{0}}^{1}\right)$ & \multicolumn{3}{|c|}{$0,655(0,655)$} & \multicolumn{3}{|c|}{$1,000(1,000)$} & \multicolumn{3}{|c|}{$1,235(0,977)$} \\
\hline$S_{q_{1}}^{0} \quad\left(S_{q_{1}}^{1}\right)$ & \multicolumn{3}{|c|}{$0,905(1,714)$} & \multicolumn{3}{|c|}{$1,000(1,000)$} & \multicolumn{3}{|c|}{$0,960(0,826)$} \\
\hline
\end{tabular}

\section{Conclusions}

The article presents a method for assessing the level of informational asymmetry in logistics systems. A qualitative assessment of the level of asymmetry allows to increase the functional stability of the logistics systems as a whole and their individual agents. For this, it is proposed to use a mathematical tools that takes into account that informational asymmetry can change the direction of real asymmetry, and real asymmetry can reduce ("turn off") the effect of informational asymmetry. The article defines a superstable condition for logistics systems in which the decisions of the duopolists in the Cournot and Stackelberg equilibrias coincide. 


\section{References}

1. F. Hayek, Economica, 4, (1937)

2. G. Akerlof, Quarterly Journal of Economics, 84, 3 (1970)

3. X. Vives, Journal of Economic Theory, 34 (1984)

4. E. Gal-or, The Review of Economic Studies, 53, 1 (1986)

5. L. Roller, B. Sinclair-Desgagne, CIRANO: Scientific

Series, https://cirano.qc.ca/pdf/publication/96s-23.pdf (1996)

6. P. Zanchettin, Journal of Economics \& Management Strategy, 15 (2006)
7. Y. Wang, Y. Li, M. Liu, Physica A, 373 (2007)

8. A.F. Ledvina, R. Sircar, SSRN Electronic Journal, https://doi.org/10.2139/ssrn.1692957 (2011)

9. A. Nagurney, D. Li, L.S. Nagurney, International Journal of Production Economics, 158 (2014)

10. J.C. Wang, L. Yang, Y.Y. Wang, Z.H. Wang, International Transactions in Operational Research, doi: 10.1111/itor.12237 (2015).

11. S. Brangewitz, J. Manegold, Theoretical Economics Letters, 6 (2016)

12. S.V. Melnikov, Odesa National University Herald. Series Economy, 22 (2017)

13. T. Puu, Chaos, Solitons \& Fractals, 1 (1991) 